\title{
Spatial Shaping of Cochlear Innervation by Temporally Regulated Neurotrophin Expression
}

\author{
Isabel Fariñas, ${ }^{1,2}$ Kevin R. Jones, ${ }^{3}$ Lino Tessarollo, ${ }^{5}$ Allison J. Vigers, ${ }^{3}$ Eric Huang, ${ }^{1}$ Martina Kirstein, ${ }^{2}$ \\ Dominique C. de Caprona, ${ }^{4}$ Vincenzo Coppola, ${ }^{5}$ Carey Backus, ${ }^{1}$ Louis F. Reichardt, ${ }^{1}$ and Bernd Fritzsch ${ }^{4}$ \\ ${ }^{1}$ Program in Neuroscience, Department of Physiology and Howard Hughes Medical Institute, University of California, San \\ Francisco, California 94143-0724, ²Departamento de Biología Celular, Universidad de Valencia, 46100 Burjassot, Spain, \\ ${ }^{3}$ Department of Biology, University of Colorado, Boulder, Colorado 80309, ${ }^{4}$ Department of Biomedical Sciences, \\ Creighton University, Omaha, Nebraska 68178, and 5Neural Development Group, Mouse Cancer Genetics Program, \\ National Cancer Institute, Frederick, Maryland 21701
}

Previous work suggested qualitatively different effects of neurotrophin $3(N T-3)$ in cochlear innervation patterning in different null mutants. We now show that all NT-3 null mutants have a similar phenotype and lose all neurons in the basal turn of the cochlea. To understand these longitudinal deficits in neurotrophin mutants, we have compared the development of the deficit in the NT-3 mutant to the spatial-temporal expression patterns of brain-derived neurotrophic factor (BDNF) and NT-3, using lac $Z$ reporters in each gene and with expression of the specific neurotrophin receptors, trkB and trkC. In the NT-3 mutant, almost normal numbers of spiral ganglion neurons form, but fiber outgrowth to the basal turn is eliminated by embryonic day (E) 13.5. Most neurons are lost between E13.5 and E15.5. During the period preceding apoptosis, NT-3 is expressed in supporting cells, whereas BDNF is expressed mainly in hair cells, which become postmitotic in an apical to basal temporal gradient. During the period of neuronal loss, BDNF is absent from the basal cochlea, accounting for the complete loss of basal turn neurons in the NT-3 mutant. The spatial gradients of neuronal loss in these two mutants appear attributable to spatial-temporal gradients of neurotrophin expression. Our immunocytochemical data show equal expression of their receptors, TrkB and TrkC, in spiral sensory neurons and thus do not relate to the basal turn loss. Mice in which NT-3 was replaced by $B D N F$ show a qualitative normal pattern of innervation at E13.5. This suggests that the pattern of expression of neurotrophins rather than their receptors is essential for the spatial loss of spiral sensory neurons in NT-3 null mutants.

Key words: neurotrophins; ear innervation; development of ear innervation; ear and neurotrophin expression; NT-3; sensory neuron survival
The inner ear develops from the otic placode that invaginates to form the otocyst by embryonic day (E) 9.5 (Fritzsch et al., 1998a). Between E9.5 and E15.5, the otocyst produces the cochlear (spiral) and vestibular sensory neurons (Ruben, 1967) that will innervate the future cochlea, saccule, utricle, and semicircular canals (Sobkowicz, 1992; Fritzsch and Nichols, 1993; Karis et al. 2001).

These otic (cochleo-vestibular) sensory neurons require brainderived neurotrophic factor $(B D N F)$ and neurotrophin $3(N T-3)$ for their survival (for review, see Fritzsch et al., 1999). In situ studies have shown that inner ear sensory epithelia express both

\footnotetext{
Received March 19, 2001; revised May 21, 2001; accepted June 1, 2001.

This work was supported in part by grants from the National Institute on Deafness and Other Communication Disorders (P 50 DC 00215), the National Organization of Hearing Research, and the Leda Sears Trust to B.F. and D.C.D.; Ministerio de Educación y Ciencia-Comisión Interministerial de Ciencia y Tecnología, Spain (SAF99-0119-C0) and Fundació la Marató de TV3 to I.F.; National Institutes of Health Grant KO1 NS01872 to A.J.V.; National Institute of Mental Health Grant 48200 to L.F.R.; and a University of Colorado Junior Faculty Development Award, a Muscular Dystrophy Association grant, and a Burroughs-Wellcome New Investigator in Pharmacology Award to K.R.J. B.F. thanks C. Miller for excellent assistance with the TEM and SEM preparations and for her dark room work and M. Christensen for her help with immunocytochemistry. L.F.R. is an Investigator of the Howard Hughes Medical Institute.

I.F., K.R.J., and L.T. contributed equally to this paper.

Correspondence should be addresssed to Dr. B. Fritzsch, Department of Biomedical Sciences, Creighton University, Omaha, NE 68178. E-mail: Fritzsch@Creighton.edu.

Copyright (C) 2001 Society for Neuroscience 0270-6474/01/216170-11\$15.00/0
}

neurotrophins, whereas otic sensory neurons express their receptors, trkB and trkC (Pirvola et al., 1992, 1994; Schecterson and Bothwell, 1994; Wheeler et al., 1994). NT-3 null mutants lose $\sim 84 \%$ of all cochlear neurons at birth (Fariñas et al., 1994; Ernfors et al., 1995; Tessarollo et al., 1997). In contrast, BDNF and trkB mutant mice lose mainly vestibular neurons (Fritzsch et al., 1995; Bianchi et al., 1996). BDNF/NT-3 or trkB/trkC double homozygous mutants lose all cochlear and vestibular neurons around birth (Ernfors et al., 1995; Minichiello et al., 1995; Schimmang et al., 1997; Silos-Santiago et al., 1997).

Initial analyses of the cochlea reported that the phenotypes of $B D N F$ and trkB mutants are restricted to type II spiral neurons that innervate outer hair cells (OHC), suggesting an effect in the radial direction (Ernfors et al., 1995; Schimmang et al., 1995). Other examination of $B D N F$ and $t r k \mathrm{~B}$ homozygous mutants revealed the presence of $\mathrm{OHC}$ afferents to the basal turn of the cochlea, suggestive of a longitudinal effect (Bianchi et al., 1996; Fritzsch et al., 1997a). Initial observations of NT-3 and trkC mutants reported a complete loss of type I spiral sensory neuron innervation of inner hair cell (IHC) (Ernfors et al., 1995; Schimmang et al., 1995). Again, others suggested that NT-3 and trkC mutants lose spiral neurons predominantly in the basal turn (Fritzsch et al., 1997a,b, 1998b). Longitudinal differences in innervation density are known in adult mammals (Ryugo, 1992), and the neurotrophins could provide the molecular basis for these differences. 
Unfortunately, available in situ data on neurotrophins and their receptors cannot explain the selective dependency of, for example, basal turn spiral neurons on NT-3 or trkC (Pirvola et al., 1994; Schecterson and Bothwell, 1994). At birth a longitudinal gradient of NT-3 (Pirvola et al., 1992) or of both BDNF and NT-3 (Wheeler et al., 1994) was reported, with the highest expression in the apex. This expression pattern does not correlate with the basal turn loss of sensory neurons in NT-3 mutants.

Now, we characterize the embryonic deficits in cochlear neurons and their projections using two independently generated $N T-3$ null mutants. We also present the developmental expression patterns of NT-3 and BDNF using lacZ inserted into the NT-3 and $B D N F$ loci as reporters. These results indicate that a temporal developmental gradient of $B D N F$ expression results in a spatial gradient of sensory neuron loss in mice lacking NT-3.

Parts of this paper have been published previously (Fritzsch et al., 1997d, 2000).

\section{MATERIALS AND METHODS}

Animal breeding and genotyping. NT-3 ${ }^{\text {lacZneo }}$ and BDNFlacZneo mice were generated and bred as previously described (Fariñas et al., 1994; Bennett et al., 1999). NT-3 ${ }^{\text {lacZneo }}$ mice were genotyped as previously described (Fariñas et al., 1994). For BDNF lacZneo mice, tail biopsies were genotyped by PCR analysis. One PCR primer (MBDSA10, GTGGAGTTCTGCTAATGAGA) was located upstream of the BDNF coding exon, and the other primer (lacZN5, GTGCTGCAAGGCGATTAAGT) was located in the lac $Z$ gene. PCR was performed in $10 \mathrm{~mm}$ Tris- $\mathrm{HCl}, \mathrm{pH} 9.0$ at $25^{\circ} \mathrm{C}, 50 \mathrm{~mm} \mathrm{KCl}, 1.5 \mathrm{~mm} \mathrm{MgCl}_{2}, 0.1 \%$ Triton X-100 with $50 \mu \mathrm{M}$ dNTPs and $0.3 \mu \mathrm{M}$ primers. PCR conditions were: 3 min at $94^{\circ} \mathrm{C}$, then 35 cycles with $30 \mathrm{sec}$ denaturation at $94^{\circ} \mathrm{C}, 30 \mathrm{sec}$ annealing at $58^{\circ} \mathrm{C}$, and 1.5 min elongation at $72^{\circ} \mathrm{C}$.

We also replaced the mouse NT-3 (also known as Ntf3) coding sequence with BDNF (Coppola et al., 2001). We analyzed the pattern of innervation of mice of one litter of these transgenic mice at E13.5 (two $N T-3^{\operatorname{tg} B D N F}$ homozygotics, two NT-3 $3^{\operatorname{tg} B D N F}$ heterozygotes, and one wild type) (see Fig. $2 D$ ). A more detailed account of the effect of NT-3 $3^{\operatorname{tg} B D N F}$ on the pattern of innervation of the cochlea in newborn mice is provided by Coppola, et al. (2001).

$\beta$-galactosidase histochemical staining. For the expression analysis, we used two to five heterozygous $N T-3^{\text {lacZneo }}$ and BDNF lacZneo animals per developmental stage from E9.5 to birth and two adult NT-3 $3^{\text {lacZneo }}$ heterozygous mice. In parallel, we examined one or two mutants per stage, and none of them showed any differences in $\beta$-galactosidase activity and distribution when compared with heterozygous littermates (data not shown). Pregnant mice were killed by cervical dislocation, and the embryos were removed rapidly and placed in ice-cold PBS. Embryos were fixed with $4 \%$ paraformaldehyde (PFA) in $0.1 \mathrm{M}$ phosphate buffer, $\mathrm{pH} 7.4$, for $2 \mathrm{hr}$. Whole embryos (E9.5-E12.5) or hemisected heads, with the brain removed to expose the ear (E13.5 to adult), were reacted as previously described (Fritzsch et al., 1997c) either at $36^{\circ} \mathrm{C}$ for $2-4 \mathrm{hr}$ or at room temperature overnight. Reacted ears were stored in $4 \%$ PFA until dissection. After dissection, the ears were whole-mounted using appropriately sized spacers to avoid distortion by the coverslip. Two ears per stage were viewed in a compound Olympus microscope using a red filter to enhance the blue reaction product. Images were captured with a Dage CCD camera $(640 \times 480$ pixels resolution $)$ and processed using ImagePro software (Media Cybernetics, Silver Spring, MD). At least two ears per stage were embedded in epoxy resin, sectioned at 1-2 $\mu \mathrm{m}$ thickness, and viewed with differential interference contrast and a red filter to enhance the blue reaction product. For the sake of simplicity, sites of accumulation of the blue reaction product resulting from the action of $\beta$-galactosidase on X-gal will be referred to here as sites of $B D N F$ or $N T-3$ expression.

Cell counts. Embryos at different stages were fixed in Carnoy's solution, embedded in paraffin, serially sectioned at $7 \mu \mathrm{m}$ in the sagittal plane, and Nissl-stained using cresyl violet as described elsewhere (Fariñas et al., 1996). Ganglion cells and numbers of pyknotic profiles were counted every fourth section in wild-type embryos and mutant littermates. Total numbers were compared using a one-tailed Student's $t$ test for statistical significance. Apoptotic profiles in the developing vestibular and cochlear ganglia were also studied in thick resin sections through ears of control and mutant littermates.

DiI tracing and whole-mount immunocytochemistry. We studied at least three ears per stage [E12.5, E13.5, E14.5, E15.5, E18.5, and postnatal day (P) 0] using DiI diffusion in perfusion fixed animals. Briefly, embryos were cold anesthetized and perfused through the heart with $4 \%$ paraformaldehyde in $0.1 \mathrm{M}$ phosphate buffer, $\mathrm{pH}$ 7.4. Filter strips soaked with the lipophylic tracer DiI (Molecular Probes, Eugene, OR) were inserted into the brainstem to selectively label the afferents to the ear (Fritzsch and Nichols, 1993). After an appropriate diff usion time $\left(2-4 \mathrm{~d}\right.$ at $\left.36^{\circ} \mathrm{C}\right)$, the ears were dissected, whole-mounted, and viewed in a compound microscope using epifluorescence illumination and a Texas Red filter set. Subsequently, the ears were defatted, incubated with an antibody against acetylated tubulin (Sigma, St. Louis, MO) for $3 \mathrm{~d}$, followed by a secondary antibody tagged with peroxidase, and reacted with diaminobenzidine. To compare the distribution of fibers to that of cells expressing NT-3, some ears that had been previously reacted to detect $\beta$-galactosidase were also immunostained with acetylated tubulin as described (Fritzsch et al., 1997c).

Immunocytochemistry. Antibodies to acetylated tubulin (see above) and antibodies to TrkB (also known as Ntrk2) and TrkC (also known as Ntrk3) were used in whole mounts and paraffin sections of Carnoy-fixed material as previously described (Fritzsch et al., 1997c; Fariñas et al., 1998). The specificity of each Trk antibody has been determined using Western blot analysis and correlation of immunohistochemistry with in situ hybridization (Huang et al., 1999).

\section{RESULTS}

\section{Expression of NT-3 and BDNF in newborn mice does not correlate with the pattern of fiber loss seen in the cochlea of the corresponding mutants}

We have taken advantage of the insertion of a lacZ reporter gene into the BDNF and NT-3 loci to monitor the endogenous expression of these neurotrophins by assessing the $\beta$-galactosidase staining pattern. In newborn mice heterozygous and homozygous for the $N T-3^{\text {lac } Z}$ or $B D N F^{\text {lac } Z}$ alleles, we used a combination of $\beta$-galactosidase staining and acetylated tubulin whole-mount immunocytochemistry to examine simultaneously the $N T-3$ and $B D N F$ expression domains and the pattern of sensory neuron fiber distribution. Notable innervation differences, but identical patterns of neurotrophin expression, between heterozygous and homozygous mutant littermates could be observed in neonates (Fig. 1).

Similar expression pattern of the lac $Z$ gene in the cochlea was observed in heterozygous and homozygous NT-3 mutants at birth (Fig. 1A-C). However, although cochleas from NT-3 heterozygous mice were heavily innervated by radial cochlear fibers (Fig. $1 B)$, there was a conspicuous absence of radial fibers to the base of the cochlea in the NT-3 mutants (Fig. $1 A, C$ ). The few fibers that were seen spiraling next to IHC toward the tip of the basal turn in NT-3 deficient cochleas were basal extensions of the remaining middle turn fibers (Fig. $1 C$ ). OHC in the basal turn of the mutants were not approached by any fibers except for the few OHCs immediately adjacent to the middle turn region (Fig. 1C). Despite the regional fiber loss observed at birth in the absence of $N T-3$, the intensity and distribution of the blue precipitate appeared uniform throughout the extent of the cochlear sensory epithelium.

In the absence of $B D N F$, the cochlea showed more subtle differences in the degree of innervation between heterozygotes and homozygotes (Fig. 1D,E). Comparison between littermates with one or two mutant $B D N F$ alleles showed a reduction in the density of radial fibers throughout the cochlea in the homozygous condition with the least pronounced difference in the base and the most obvious in the apex. In fact, portions of the apex were almost devoid of radial fibers (Fig. 1E) (Bianchi et al., 1996). The 
Figure 1. Distributions of nerve fibers in the cochlea of $N T-3$ and BDNF heterozygous and homozygous mutant mice at birth. Whole-mounted cochleas from a newborn $N T-3$ homozygous mutant $(A, C)$ and an NT-3 heterozygous littermate $(B)$, a $B D N F$ heterozygous mutant $(D)$, and a $B D N F$ homozygous mutant $(E)$ showing the distribution of $N T-3 \quad(A-C)$ and of $B D N F(D, E)$ as revealed by $\beta$-galactosidase histochemistry and the distribution of nerve fibers as revealed by acetylated tubulin immunocytochemistry. Notice that the cochlea is labeled uniformly throughout its extent by the blue histochemical product. In NT-3 null mice, no radial fibers are present in the basal turn $(A$, $C)$. The only innervation present in this turn is supplied by the few fibers diverted from the middle turn that extend along the longitudinal axis of the cochlea next to inner hair cells $(C$, crossed arrows). The only outer hair cells in the basal turn approached by afferent fibers were those adjacent to the middle turn (arrow). This contrasts with the presence of numerous radial fibers innervating inner and outer hair cells in the basal turn of an NT-3 heterozygous littermate $(B$, arrows). The density of radial fiber, as revealed by an increase in the spacing between radial fiber bundles, is reduced in the absence of $B D N F(E)$ when compared with the heterozygous condition $(D)$. This reduction in fiber density is stronger in the apex of $B D N F$ null mutants. Thus, the homogeneous distribution of NT-3 and BDNF at birth does not explain the selective loss of basal turn spiral neurons in NT-3 null mutants or the reduced density of radial fibers in the apex of $B D N F$ null mutants. ggl, Ganglion; $R F$, radial fiber bundles. Scale bars, $0.1 \mathrm{~mm}$.

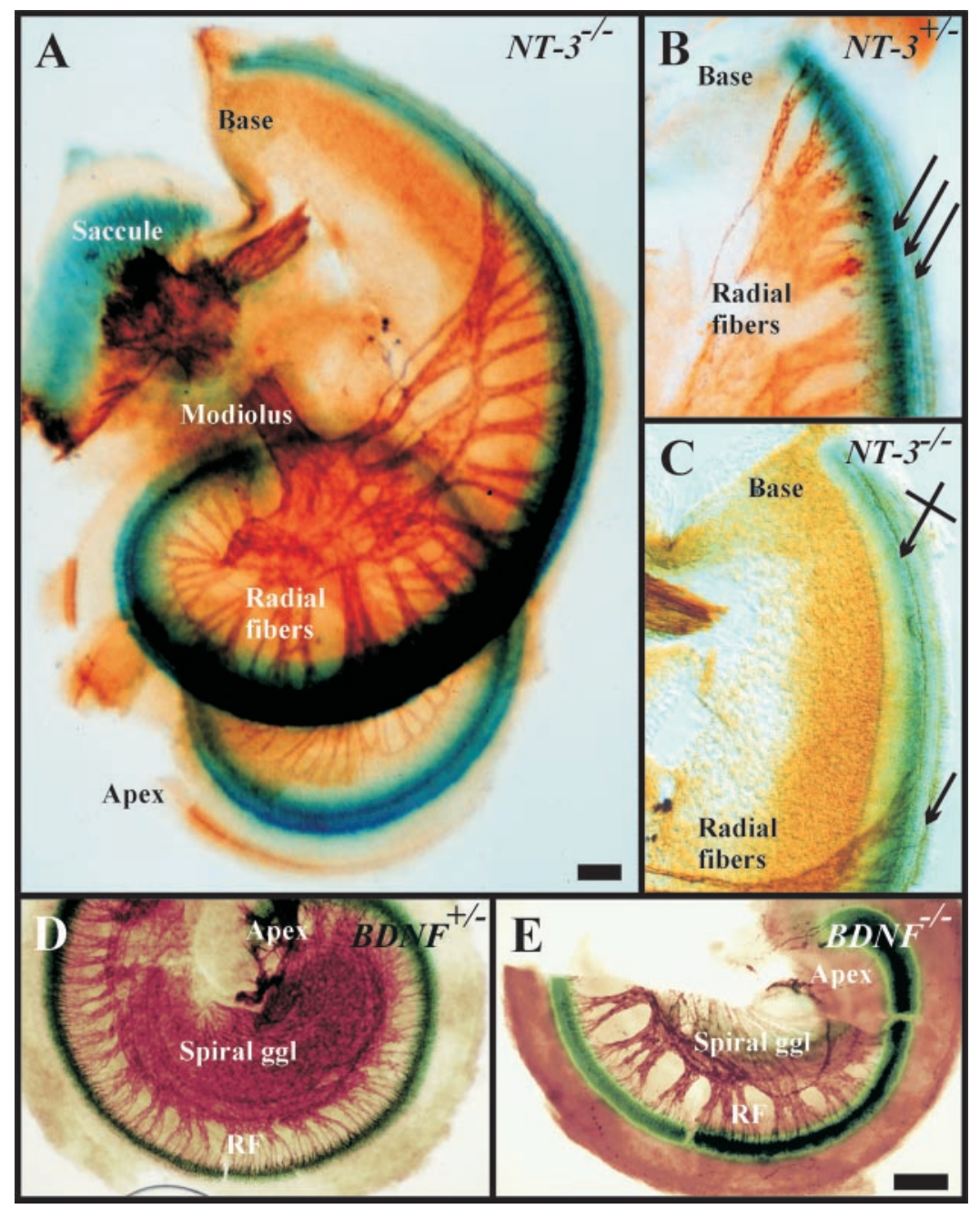

expression of endogenous $B D N F$, as revealed by the reporter gene, showed no apparent regional differences throughout the cochlea that could readily explain the spatial effect of the spatially restricted fiber loss in the $B D N F$-deficient animals.

\section{Other NT-3 null mutants have a similar phenotype}

Reports describing different phenotypes in the cochlea of NT-3deficient animals have used mouse strains carrying mutations independently generated in different genetic backgrounds [compare Ernfors et al. (1995), Fritzsch et al. (1997c)]. To determine whether genetic background is responsible for the different findings, we examined the cochleas of an independently generated NT-3 mutant (Ernfors et al., 1995). As illustrated in Figure 2E,F, the phenotypes, as shown by DiI tracing, were essentially the same in both mutant strains at birth. Similar to our previous data (Fritzsch et al., 1997c) (Fig. 1), we observed a complete loss of neurons in the basal turn, a complete absence of radial fibers to the sensory epithelium in this turn, and tangential extension of fibers from the middle turn along the basal turn IHC. The third available NT-3 null mutation (Liebl et al., 1997; Tessarollo et al., 1997) shows a similar loss of basal turn sensory neurons (Coppola et al., 2001). Thus, all three NT-3 null mutants have a uniform phenotype.

The topology of the projection from the cochlea to the brainstem was also analyzed by applying DiI to both the apical and basal turns. After diffusion of the dye, the implantation sites were verified in whole-mounted cochlea. Brains of animals with comparable injection sites and comparable spread of DiI along the cochlea were chosen for analysis. We assume that these animals had both topologically and quantitatively comparable injections. In coronal sections of wild-type animals, two distinct bands of projection fibers ended in the ventral cochlear nucleus (Fig. 2G). The more ventrolateral projection is from the middle turn, the more dorsomedial projection comes from the basal turn. In the NT-3 mutants, there were also two visible bundles from the middle and basal turn of the cochlea, respectively, but the segregation was less distinct (Fig. 2H). Both the wild-type and the NT-3 mutant show efferent fiber bundles, suggesting that sections were taken at comparable levels (Fig. 2G,H).

\section{Cochlear afferent fibers to the basal turn are lost at E13.5 in NT-3 mutants}

In control animals, it is first possible to visualize cochlear neurons and their projections to the developing cochlear duct by DiI labeling at E12.5 (Fig. $2 A$ ). In both control (Fig. $2 A$ ) and NT-3 mutant embryos (Fig. $2 B$ ), fibers extend from the sensory neurons to the developing cochlea at this stage. In the mutant, however, fewer fibers were labeled. In contrast to control animals, only one of four mutant embryos had any fibers projecting to the basal turn. In all mutants, at least some of the radial afferents from the middle turn extended tangentially toward the noninnervated 


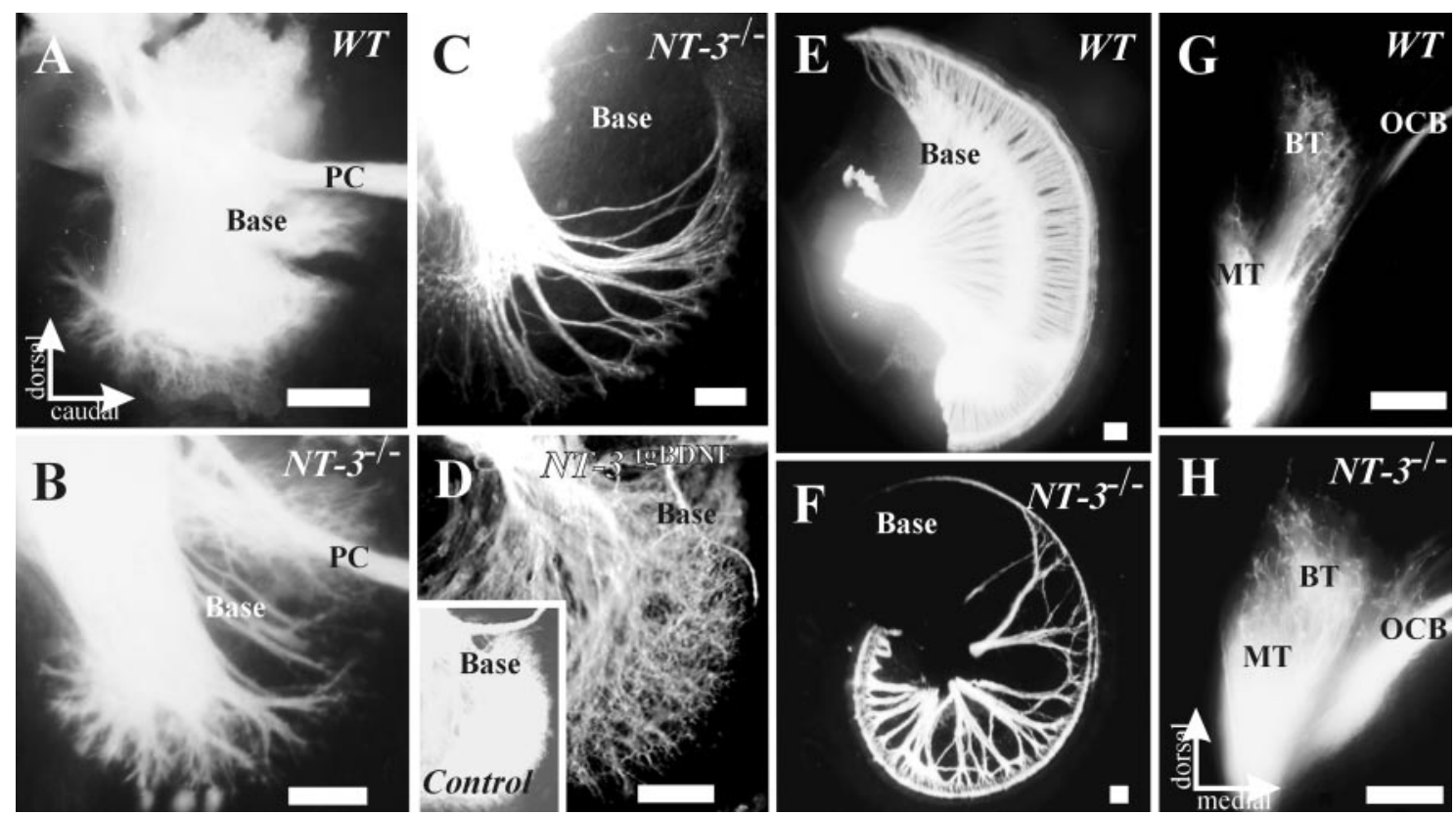

Figure 2. Development of cochlear afferent innervation at E12.5 $(A, B), \mathrm{E} 13.5(C, D$, inset $)$, and $\mathrm{P} 0(E, F)$, and of central projections at $\mathrm{P} 0(G, H)$. Arrows in $A$ show orientation for $A-F$; arrows in $H$ show orientation for the coronal sections of $G$ and $H$. Outgrowth of afferents $(A, B)$ is labeled with DiI in E12.5 wild-type $(A)$ and $N T$-3 mutant $(B)$ littermates. Note projection to the basal turn in both cases. At E13.5, the $N T$-3 mutant $(C)$ lacks radial afferents in the base of the cochlea. In contrast, NT-3 $3^{\text {tgBDNF }}$ mutants show a pattern of innervation reminiscent of same age wild-type animals (inset) with an overall reduced density of innervation but a clear innervation of the basal turn $(D)$. Newborn NT-3 mutant mice from a different genetic strain (Ernfors et al., 1994) show comparable patterns of innervation $(E-F)$. Compared with the dense radial afferent bundles in the wild types $(E)$, notice the complete absence of radial afferents in the basal turn of mutants $(F)$ and exclusive innervation of inner hair cells. Cochlear afferents to the brainstem in control $(G)$ and in NT-3 mutant $(H)$ littermates show a topologically restricted projection from the base and the middle turn to the more dorsal and ventral aspects of the ventral cochlear nucleus, respectively. The distinction between the two areas of projection is less pronounced in NT-3 mutants, presumably because the remaining sensory fibers occupy the areas normally innervated by the lost afferents. Comparable coronal section planes are indicated by the presence of olivocochlear efferent fibers $(G, H)$. BT, Basal turn; $M T$, middle turn; $O C B$, olivo-cochlear bundle; $P C$, fibers to the posterior crista; $W T$, wild type. Scale bars, $100 \mu \mathrm{m}$.

basal turn (Fig. 2B). A similar tangential projection was never seen in control embryos.

In control embryos at E13.5, there was a prominent radial projection from basal turn cochlear ganglion neurons to the basal turn sensory epithelium (Fig. 2D, inset). In contrast, radial fibers were completely absent in the basal turn of NT-3 mutants (Fig. $2 C$ ), and many fewer labeled cochlear neurons and fibers were present in the rest of the cochlea. Although not a single cochlear neuron fiber deviated from its normal radial trajectory in the control animals, there was a prominent deviating projection of middle turn cochlear neuron fibers in the mutants directed toward the basal turn, spiraling along the cochlea next to inner hair cells (Fig. 2C).

In control embryos and NT-3 mutant embryos at E14.5 and later embryonic stages, the distributions of sensory neurons and their projections within the cochlea did not differ qualitatively from the patterns observed at birth (Fritzsch et al., 1997c) (Fig. 1). In control embryos, a continuous and dense array of neurons in all turns of the cochlea extended radial fibers to the sensory epithelium. The density of radial bundles in NT-3 mutants, however, was reduced throughout the developing cochlea except for the very apical turn. Here, densely packed radial fibers were seen that appeared qualitatively similar to those in control animals regarding their spacing interval (Fig. $1 B, C$ ). In NT-3 mutants, however, essentially no neurons survived in the basal turn and, subsequently, no radially oriented fibers were found in this portion of the cochlea (Fig. 1). In the noninnervated basal turn, fibers from the middle turn portion were seen extending tangentially along the line of IHC toward the tip of the basal turn (Fig. 1C).

\section{Cochlear afferent fibers to the basal turn are rescued at E13.5 in NT-3 ${ }^{\text {tgBDNF}}$ mice}

We also compared the pattern of innervation of NT-3 mutants at E13.5 with that of same-aged transgenic animals in which the mouse $N T-3$ coding sequence was replaced with $B D N F$ (Fig. 2C,D). At this stage, the basal turn innervation in $N T-3^{\operatorname{tg} B D N F}$ animals compared qualitatively well to wild-type littermates (Fig. 2D, inset). Specifically, there was a striking difference in the pattern of innervation of the basal turn of the cochlea compared with NT-3 mutants (Fig. $2 C, D$ ) suggesting a near complete rescue of the NT-3 phenotype in this transgenic mouse line. This rescue of basal turn afferent projection persisted in newborn transgenic mice, and a full account of this phenotype is given by Coppola et al. (2001).

\section{Most cochlear neurons die by E15.5 in the absence of NT-3}

The numbers of neurons present in the cochlear ganglion at different stages of embryonic development have been quantitated, and the data are presented in Table 1. At E11.5, the vestibular and cochlear ganglia are not yet separate structures, so the numbers of neurons in the combined (otic) ganglion are presented. As shown in Table 1 , there are only small, statistically insignificant reductions in the numbers of otic neurons at E11.5 and E13.5 in NT-3 mutants. Between E13.5 and E15.5, however, 73\% of the neuronal complement of cochlear neurons are lost in the NT-3 mutants. The neuronal loss is not homogeneously distributed. At E15.5, all spiral neurons in the basal turn have completely disappeared, whereas a number of neurons are still found in middle and apical 


\begin{tabular}{|c|c|c|c|c|c|c|}
\hline & & $\mathrm{E} 11.5^{a}$ & E13.5 & E15.5 & E17.5 & $\mathrm{P} 0^{b}$ \\
\hline \multirow[t]{3}{*}{ Otic ggl } & $+/+$ & $8615 \pm 2107$ (3) & $14,440 \pm 1766(3)$ & & & \\
\hline & $-1-$ & $7619 \pm 583(4)$ & $12,054 \pm 1369(3)$ & & & \\
\hline & $\%$ red. & 11 & 17 & & & \\
\hline \multirow[t]{3}{*}{ Cochlear } & $+/+$ & & $8899 \pm 656(3)$ & $8697 \pm 877(3)$ & $7646 \pm 1682(2)$ & $8082 \pm 1132(3)$ \\
\hline & $-1-$ & & $7542 \pm 1366(3)$ & $2336 \pm 375(3)$ & $957 \pm 5(4)$ & $1284 \pm 120(3)$ \\
\hline & $\%$ red. & & 15 & $73^{*}$ & $86^{* *}$ & $84^{* *}$ \\
\hline
\end{tabular}

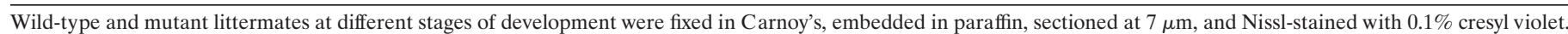

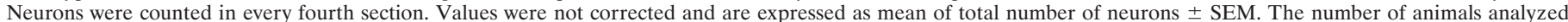

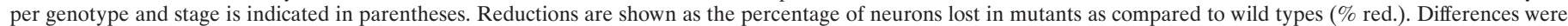
tested using a one-tailed Student's $t$ test.

${ }^{a}$ At E11.5, the cochlear and vestibular subdivisions of the otic ganglion (otic ggl) cannot be distinguished and, therefore, are considered together.

${ }^{b}$ Values in newborns (P0) were published previously (Fariñas et al., 1994).

$* p<0.05, * * p<0.005$.

\begin{tabular}{|c|c|c|c|c|c|}
\hline & & $\mathrm{E} 11.5^{a}$ & E13.5 & E15.5 & E17.5 \\
\hline Otic ggl & $\begin{array}{l}+/+ \\
-/-\end{array}$ & $\begin{array}{r}1.2 \pm 0.7(3) \\
3 \pm 0.8(4)\end{array}$ & & & \\
\hline Cochlear & $\begin{array}{l}+/+ \\
-/-\end{array}$ & & $\begin{array}{l}0.7 \pm 0.1(3) \\
9.3 \pm 1.1(3)^{*}\end{array}$ & $\begin{array}{c}0.8 \pm 0.1(3) \\
17.1 \pm 4.0(3)^{*}\end{array}$ & $\begin{array}{l}0.9 \pm 0.3(2) \\
1.3 \pm 0.5(4)\end{array}$ \\
\hline \multicolumn{6}{|c|}{$\begin{array}{l}\text { Wild-type and mutant littermates at different stages of development were fixed in Carnoy's, embedded in paraffin, sectioned } \\
\text { at } 7 \mu \mathrm{m} \text {, and Nissl-stained with } 0.1 \% \text { cresyl violet. Pyknotic figures were counted in every fourth section, and the total } \\
\text { number was calculated accordingly. Values are expressed as percentage of pyknotic figures relative to the total number of } \\
\text { cells (see Table 1) and represented by mean } \pm \text { SEM. The number of animals analyzed per genotype and stage is indicated } \\
\text { in parentheses. Differences between mutants and wild types were tested using a one-tailed Student's } t \text { test. } \\
{ }^{a} \text { At E11, the cochlear and vestibular subdivisions of the otic ganglion (otic ggl) cannot be distinguished and, therefore, are } \\
\text { considered together. } \\
{ }^{*} p<0.05 \text {. }\end{array}$} \\
\hline
\end{tabular}

turns (data not shown). By E17.5 loss of neurons in mutants $(86 \%)$ is similar to that previously described in neonates $(84 \%)$ (Fariñas et al., 1994).

This dramatic embryonic loss can be most simply explained by cell death of cochlear sensory neurons, especially of those in the basal turn. We, therefore, examined the distribution and frequency of apoptotic profiles in control and NT-3 mutant littermates (Table 2). Our previous work has not revealed a difference between scoring apoptosis by terminal deoxynucleotidyl transferase-mediated biotinylated UTP nick end-labeling or by counting pyknotic profiles after cresyl violet staining (Fariñas et al., 1996). Therefore, we present here only the data gathered from conventionally stained material. Consistent with the loss of a large fraction of cochlear neurons between E13.5 and E17.5, we found increased cell death at E13.5 and E15.5 in the ganglia of animals deficient in NT-3. In the cochlear ganglion, many of the pyknotic profiles were seen near its posterior aspect and, therefore, most of the dying cells are likely to be neurons that would have projected to the basal turn. These data suggest that, in the absence of NT-3, the majority of cochlear sensory neurons die between E13.5 and E15.5. In summary, there appears to be a loss of the sensory projection to the basal turn before E13.5 that is followed by elevated apoptosis of neurons over the following several days.

To determine whether all cochlear neurons can respond to $B D N F$ and NT-3, we have examined Trk receptor distribution, using antibodies that specifically recognize $\operatorname{TrkA}, \operatorname{Trk} \mathrm{B}$, and $\operatorname{Trk} \mathrm{C}$ in histological sections (Fariñas et al., 1998). Results in Figure 3 show that both trkB and trkC are expressed in otic ganglia from
E11.5 onward. Starting at E13.5, when cochlear and vestibular sensory neurons can be first recognized as separate ganglia, we detect TrkB and TrkC coexisting in the cochlear sensory neurons (Fig. 3E-G). Moreover, these receptors appear to be prominently expressed in the growing neuronal processes invading the sensory epithelia (Fig. $3 A, F$ ). The apparently ubiquitous expression of TrkB and TrkC receptors in otic neurons suggests that they can respond to either $B D N F$ or $N T-3$ and that the specific losses observed in the mutants are not attributable to differential expression of Trk receptors.

\section{BDNF expression in the developing cochlea}

In whole-mounted ears from $B D N F^{\text {lacZneo }}$ heterozygous E10.5 embryos, strong $B D N F$ expression was observed in the posterior margin of the forming cochlear duct (Fig. $4 A$ ). The E11.5 otocyst showed distinct aggregations of $B D N F$-expressing cells in the canal sensory epithelia. However, expression in the posterior canal epithelium was continuous with the expression in the expanding cochlear duct (Fig. 4B). Surprisingly, the expression at E12.5 was restricted to the sensory epithelia of the vestibular system, in particular of the semicircular canals (Fig. 4C). In contrast to the strong expression of $B D N F$ observed in the growing cochlear duct at E11.5 (Fig. $4 A, B$ ), there was only a very faint expression in the E12.5 cochlea that was restricted to the apical growing tip (Figs. 4C, $5 A$ ). At E13.5 and E14.5 the expression of $B D N F$ in the semicircular canals, utricle, and saccule was even more pronounced (Fig. $4 D$ ) and, in the cochlea, $B D N F$ expression became stronger and extended further along the length of the cochlea (Fig. $4 D$ ), but expression was not detected in the basal 


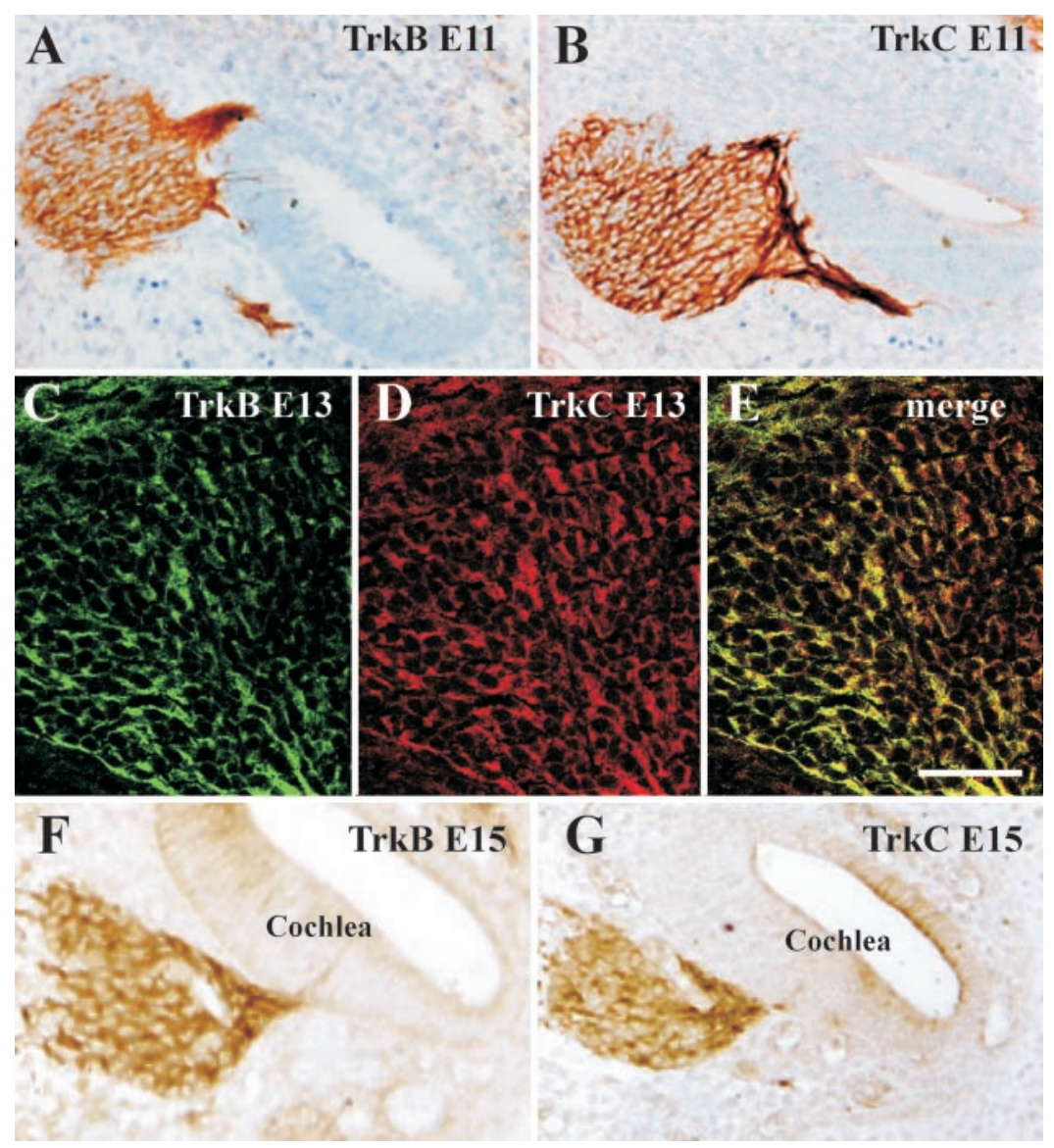

Figure 3. Developmental expression of $\operatorname{trk} \mathrm{B}(A, C, E, F)$ and trkC $(B, D, E, G)$ in developing otic sensory neurons at $\mathrm{E} 11.5(A, B)$, E13.5 $(C-E)$, and E15.5 $(F, G)$. The distribution of the trk proteins was revealed using specific primary antibodies (Fariñas et al., 1998) and peroxidase $(A, B, F, G)$, fluorescein $(C, E)$, or rhodamine $(D, E)$-conjugated secondary antibodies. trkB and trkC are expressed in all otic neurons at early stages $(A, B)$ and in all cochlear neurons until at least E15.5 $(F, G)$, respectively. Fluorescent double labeling at E13.5 for both trkB and trkC indicates that all cochlear neurons express both trk proteins $(C-E)$. Scale bar (shown in $E$ ): $A, B, F, G, 100 \mu \mathrm{m} ; C-E, 25 \mu \mathrm{m}$. turn. At E16.5 BDNF expression was seen throughout the cochlea, similar to the distribution found at birth (Fig. 1). Therefore, expression of $B D N F$ in the growing cochlea develops in an apicalto-basal gradient and does not reach the base until E16.5.

Sections through the otocyst showed that $B D N F$ is initially expressed in the otocyst wall at E10.5 and bears no clear relationship with future sensory epithelia. After the expression shifted to the future sensory epithelia at E11.5, BDNF expression in the utricle, saccule, and canal epithelia $B D N F$ was predominantly in what appeared to be differentiating hair cells (data not shown). However, BDNF expression in the cochlea was not seen in cochlear hair cells before E15.5. In the future sensory epithelium of the cochlea, little $B D N F$ expression was seen at E12.5. In fact, at this stage, when very faint expression is seen in the growing cochlear apex, the $\beta$-galactosidase product is found in nonsensory areas, specifically in what will become the Reissner's membrane (Fig. 5B), which separates the endolymph containing medial scala from the perilymph containing vestibular scala. At E15.5 and onward, an apical-to-basal gradient of cochlear BDNF expression could be detected. $B D N F$ expression was clearly seen in IHC and $\mathrm{OHC}$ in the basal turn by E17.5 and later (Fig. $6 G, H$ ), but even then, the area of the epithelium expressing this neurotrophin was larger in the apex (Fig. 6E,F). In fact, diff use labeling persisted in the apex even at birth in both hair cells and supporting cells (Fig. 6F).

\section{NT-3 expression in the developing cochlea}

In whole-mounted ears from NT-3 $3^{\text {lacZneo }}$ heterozygous E10.5 embryos, we detected only a single patch of $\beta$-galactosidase expression near the anteroventral aspect. This patch may represent the combined anlage of utricle, saccule, and cochlea (Fig. 4E-H). At E11.5, there are two discrete domains of $\beta$-galactosidase: a more dorsal patch, corresponding to the utricle, and a more ventral patch, corresponding to the saccular-cochlear anlage (Fig. 4F). The latter showed more intense staining in the rostroventrally oriented tip of the growing cochlear duct. By E12.5, the segregation between the utricle and the saccular-cochlear anlage was more distinct (Fig. $4 G$ ), and a gradient of $\beta$-galactosidase staining along the cochlear-saccular axis became apparent. In fact, the future saccule expressed lacZ only in its inferior half (Fig. 4G). By E13.5, the ear has reached its definite form (Morsli et al., 1998), and three areas of $\beta$-galactosidase expression can be distinguished (Fig. 4H) corresponding (dorsal to ventral) to the utricle, the saccule, and the cochlea, except for the growing tip of the latter (Figs. $4 \mathrm{H}, 5 \mathrm{C}$ ). In addition, weaker expression appeared around the canal sensory epithelia at this stage in development. From E14.5 to birth, the pattern of lacZ staining in the ear remained essentially identical to that found at E13.5, except that the entire cochlea became positive. Therefore, NT-3 appears to be expressed in the cochlea as it grows in longitudinal extent.

At the cellular level, the embryonic expression of NT-3 in the cochlear sensory epithelium shows dynamic spatiotemporal changes, including a longitudinal base-to-apex progression and a change in cell type expressing this neurotrophin (embryonic expression by supporting cells; neonatal expression by IHC). In sections through the cochlear epithelium, the blue $\beta$-galactosidase product was present throughout the developing sensory epithelium at E12.5 (Fig. 5C,D). From E14.5 onward, NT-3 expression became restricted to supporting cells of the cochlear epithelium, 


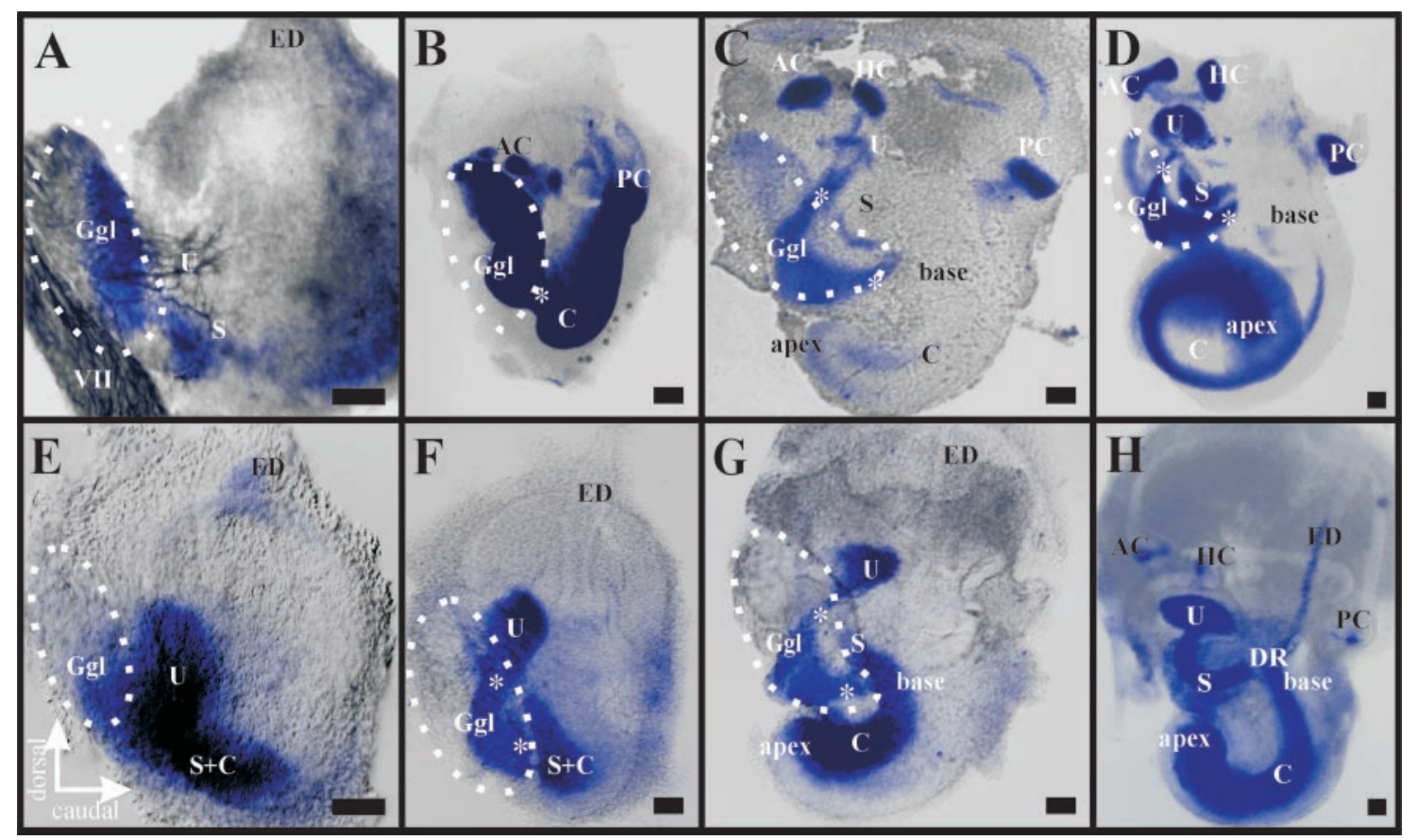

Figure 4. Developmental expression of endogenous $B D N F(A-D)$ and NT-3 $(E-H)$ as revealed by $\beta$-galactosidase histochemistry in whole-mounted cochleas from heterozygous animals with a lacZ reporter gene inserted into the BDNF and NT-3 locus, respectively. Arrows in $E$ indicate orientation. $B D N F$ expression is first detected at E10.5 $(A)$. Expression is strongest in the posteroventral aspect, but it also forms a crest around the anterior and dorsal aspect. The anteroventral aspect adjacent to the forming otic ganglion is notably devoid of $B D N F$ labeling. Interestingly, this area receives the first growing fibers $(A)$. By E11.5 $(B), B D N F$ expression in the posteroventral quadrant has intensified and is related to the growing cochlear duct, the semicircular canal sensory epithelia, and the forming cochleovestibular ganglion $(G g l)$. Streaks of $\beta$-galactosidase-positive cells $(*)$ were seen apparently migrating away from the otocyst and toward the forming ganglion and were even more apparent at E12.5 $(C)$ because of the more distant spacing of the epithelia in the growing otocyst. Interestingly, $B D N F$ expression in the growing cochlea is sharply downregulated at E12.5, except for a faint expression restricted to the growing tip $(C)$. The utricle $(U)$ and saccule $(S)$ show only faint and restricted expression at this stage. At E13.5 $(D)$ and later, the expression remains rather stable in all sensory epithelia, except for a progressive upregulation of $B D N F$ that proceeds toward the base of the cochlea. In contrast to $B D N F$, expression of $N T$-3 at E10.5 $(E)$ forms two continuous patches, the primordia of the future utricle and of the future saccule and cochlea. Faint NT-3 expression is also visible in the forming otic ganglion $(\mathrm{Ggl})$, in streaks of cells extending from discrete regions of the otocyst to the otic ganglion $\left(^{*}\right)$, and in the endolymphatic duct. By E11.5 $(F)$, the $\beta$-galactosidase-positive utricle and saccule + cochlea $(S+C)$ have segregated. By E12.5 $(G)$, the NT-3-positive portion comprises only a fraction of the total otic ganglion, and the saccule and cochlea are beginning to segregate. By E13.5 $(H)$, the utricle, saccule, and cochlea are anatomically distinct from each other, and all of them are intensely positive. Note that the ganglion was removed for clarity in $H$. The gap between the saccule and the cochlea turns into the ductus reuniens $(D R)$. There is some expression of $N T$ - 3 in the sensory cristae of the three semicircular canals (anterior, horizontal, posterior). $A C$, Anterior crista; $C$, cochlea; $E D$, endolymphatic duct; $G g l$, otic (cochleovestibular) ganglion; $H C$, horizontal crista; $P C$, posterior crista. Scale bars: $100 \mu \mathrm{m}$.

such as Deiter's cells, Pillar cells, and Border cells with limited, if any, expression in sensory hair cells during embryonic development. At birth, very faint NT-3 expression could be found in IHC of the basal, but not the apical, turn (Fig. 6A-D). In the middle and apical turns, expression was strongest in Deiter's cells and their phalangeal processes, followed by nearby Pillar cells (Fig. $6 B)$. There was also a shift in expression from outer to inner Pillar cells following an apical-basal gradient (Fig. 6B,D). The greater epithelial ridge (GER) is an embryonic structure that disappears in neonatal development, giving rise to the inner cochlear sulcus and the inner hair cells. Many of these cells expressed NT-3 as assessed using the $L a c Z$ reporter. In fact, around birth some were more strongly labeled than the IHC (Fig. 6D). Thus, NT-3 expression was detected in supporting cells, but not in hair cells during embryonic development.

\section{BDNF and NT-3 expression outside the sensory epithelia}

In contrast to some previous in situ hybridization studies (Pirvola et al., 1992, 1994), but in agreement with others (Schecterson and Bothwell, 1994), our data suggested that some cells delaminating from regions of the various sensory epithelia express either $B D N F$ or NT-3. Specifically, cells delaminating from the utricle, saccule, and the basal turn of the cochlea express NT-3, whereas cells delaminating from the apical turn of the cochlea, the utricle, and the canal epithelia express $B D N F$ (Fig. 4). In sections, these delaminating cells appeared to derive from discrete areas of the sensory epithelia that typically showed no other lacZ-positive cells. This suggests that BDNF and NT-3 expression are induced at the time of delamination. Expression of $\beta$-galactosidase does not colocalize with the presence of differentiated neurons, as identified using Trk B and Trk C immunocytochemistry (Fig. 3). These delaminated cells migrate away from the otocyst and are likely to constitute the precursor cells for otic sensory neurons as they aggregate near and occupy a region next to the differentiated otic sensory neurons. The neurotrophin-expressing cells are likely to constitute an early source of neurotrophins next to the forming otic sensory neurons.

\section{DISCUSSION}

The lack of $N T-3$ or $B D N F$ results invariably in losses of cochlear neurons with clear spatial bias. NT-3 deficient mice lose as many as $84 \%$ of the cochlear neurons, resulting in reduced density of 


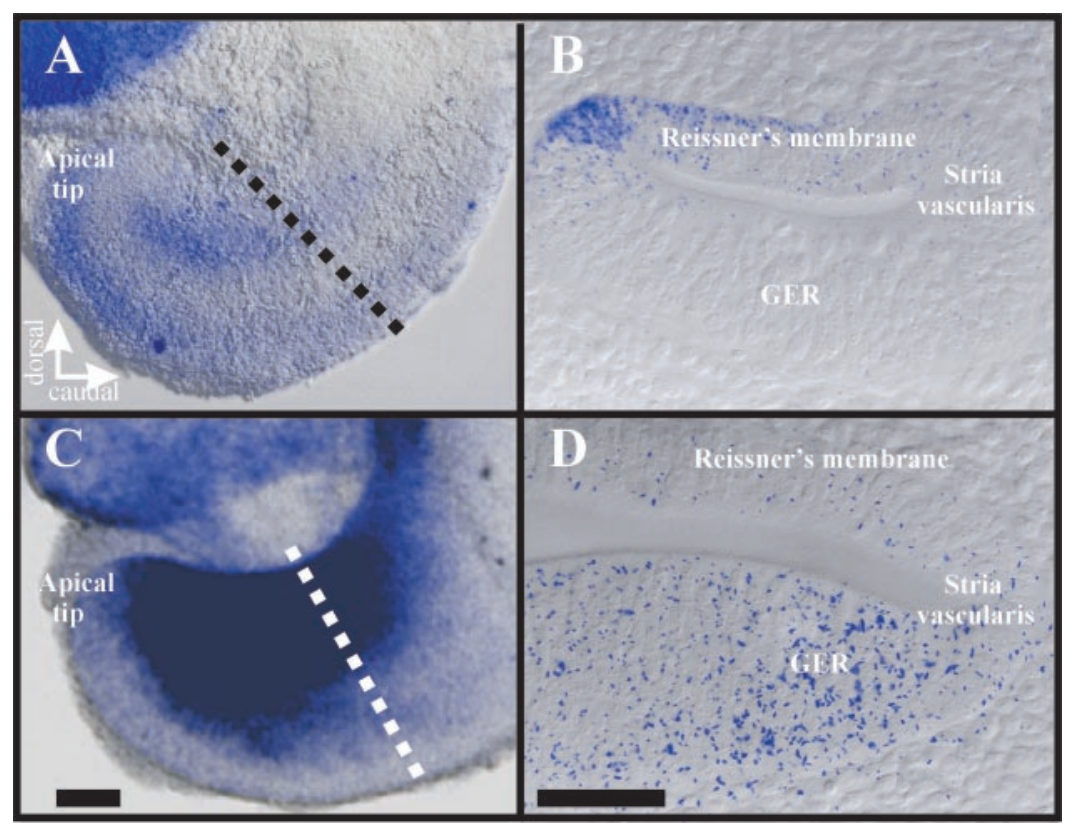

Figure 5. Expression of $B D N F(A, B)$ and $N T-3(C, D)$ in the cochlea at E12.5. Arrows in $A$ indicate orientation, and dashed lines in $A, C$ indicate plane of section for $B, D$. Note that $B D N F$ expression is very faint and restricted to the apex of the cochlea $(A)$. In contrast, NT-3 expression is more robust, although it is absent from the very apical tip $(C)$. Plastic sections $(10 \mu \mathrm{m}$ thick $)$ of X-gal-reacted cochleas show that $B D N F$ expression in the base is restricted to an area of the cochlear duct that will become the Reissner's membrane $(B)$. In contrast, $N T-3$ expression is seen throughout the greater epithelial ridge (GER), an area that will become the organ of Corti and the inner spiral sulcus. Scale bars, $100 \mu \mathrm{m}$.

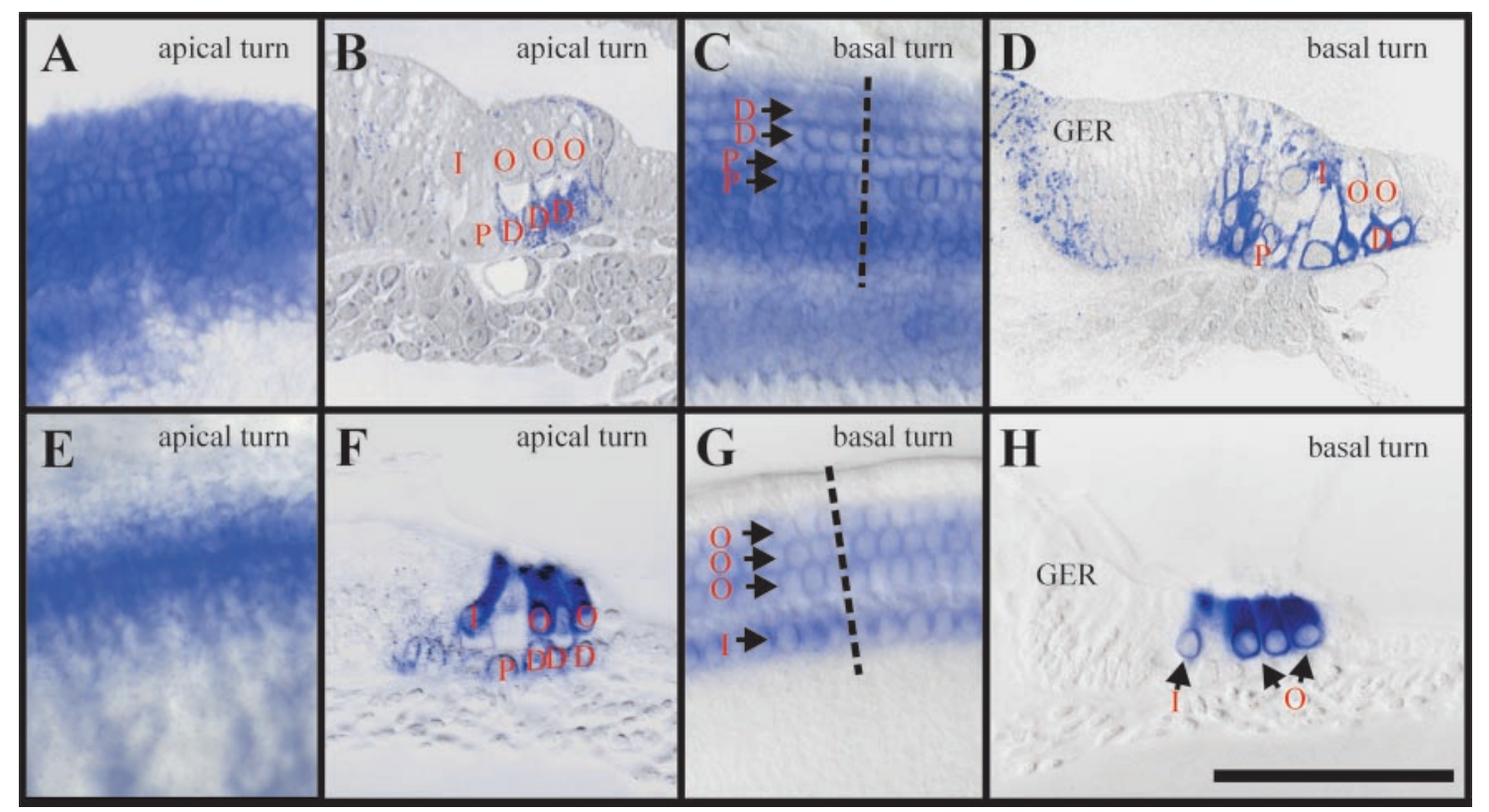

Figure 6. Expression of NT-3 $(A-D)$ and $B D N F(E-H)$ in the cochlea at birth as seen in whole mounts $(A, C, E, G)$ and in $10-\mu$ m-thick $(F, H)$ or 2 - $\mu$ m-thick $(B, D)$ plastic sections. Note that in the apical turn $(A, B, E, F)$, neither $N T-3(A, B)$ nor $B D N F$ expression $(E, F)$ is restricted to hair cells. In fact, $N T-3$ expression is predominantly seen in supporting cells that also express some $B D N F$. In contrast, in the basal turn $(C, D, G, H), B D N F$ expression is restricted to hair cells $(G, H)$, whereas $N T-3$ is expressed by inner hair cells and their surrounding supporting cells. $D$, Deiter's cells; $G E R$, greater epithelial ridge; $I$, inner hair cells; $O$, outer hair cells; $P$, Pillar cells. Scale bar, $100 \mu \mathrm{m}$.

projections in the middle and apical turns and a complete loss of radial projections to the basal turn (Fritzsch et al., 1997a). Absence of $B D N F$ results in a modest reduction of cochlear neurons and their projections, with the largest reduction in the apical turn (Bianchi et al., 1996). We characterize for the first time the cochlear deficits during embryonic development caused by the absence of NT-3. In addition, we compare the distribution of these neurotrophins and their receptors during prenatal development to determine how spatially biased deficiencies are produced by the absence of a single neurotrophin. We also compare the pattern of loss in three independently generated NT-3 null mutations (Ernfors et al., 1995; Liebl et al., 1997) and show strik- ingly similar phenotypes (Fig. 2) (Coppola et al., 2001). Thus, all NT-3 null mutants share one phenotype, loss of basal turn sensory neurons, reduction of outer hair cell innervation, and retention of inner hair cell innervation. We cannot explain why Ernfors et al. (1995) concluded that all inner hair cell innervation and the central auditory projections are lost in their NT-3 null mutant because our data clearly show that this is not the case (Fig. 2).

The generation of cochlear neurons proceeds in a basal-toapical direction, whereas birth of cochlear hair cells follows the opposite gradient, from apex to base (Ruben, 1967). During embryonic development, all cochlear neurons appear to express both trk $\mathrm{B}$ and $t r k \mathrm{C}$, and, therefore, can respond to either neuro- 
Figure 7. This scheme depicts the dynamics of BDNF (green) and NT-3 (pink) expression during cochlear development (left column) and the effects of transgenes and null mutations (right column). Note that at E12.5, BDNF is restricted to the apex of the cochlea, whereas NT-3 is prominently expressed in the base and middle turn, mainly around the three rows of outer hair cells. Sensory neurons (red circles) have become postmitotic in the basal half and extend their fibers. By E14.5, the expression of $B D N F$ has expanded toward the most basal part of the middle turn (mainly in inner hair cells), whereas NT-3 expression has expanded toward the growing apex (mainly in outer hair cells). At E16.5, expression of both $B D N F$ and $N T-3$ extends throughout the cochlea longitudinally. However, the basal turn expresses NT-3 around all hair cells and in inner hair cells, whereas the apex has no expression in or around inner hair cells. In contrast, $B D N F$ expression is found in all hair cells as well as faintly in supporting cells in the apex, whereas it is restricted to hair cells in the middle and basal turns. The arrows (Age, Maturation) refer to hair cells only. NT-3 null mutants (right column, middle) have no neurotrophin to support basal turn sensory neurons. Surviving middle turn sensory neurons rearrange their axonal trajectory toward the base. This seems to reflect the progressive upregulation of $B D N F$ in inner hair cells (bottom). In contrast, the effect of $B D N F$ null mutation becomes apparent later and in the apex. Replacing NT-3 with $B D N F$ restores the innervation of the basal turn (top). We propose that the longitudinal gradients, which mimic the age gradient of the cochlea in the case of $B D N F$ and the maturation gradient of the cochlea in the case of $N T-3$, are responsible for the specific reduction of sensory neurons in the base of NT-3 null mutants and in the apex of BDNF null mutants. IHC's, Inner hair cells; $O H C$ 's, outer hair cells.

\section{Developmental dynamics}
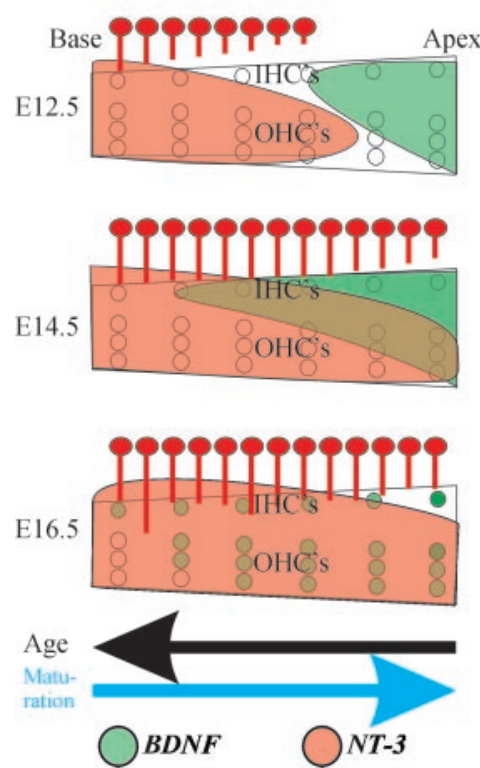

Transgenics and mutants
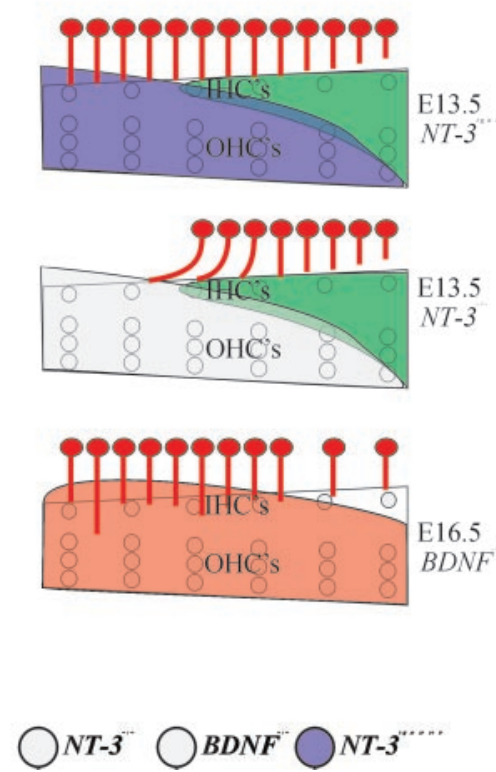

trophin (Fig. 3). However, the distributions of BDNF and NT-3 in the cochlear epithelium show very different longitudinal and radial developmental dynamics. Despite expression in nonsensory areas of the apex, BDNF expression appears to be largely restricted to hair cells (Pirvola et al., 1992, 1994; Schecterson et al., 1994; Wheeler et al., 1994) following the age gradient of hair cell proliferation. In contrast, NT-3 expression in the cochlear epithelium follows the maturational gradient of the cochlea, progressing from base to apex (Pujol et al., 1998). The earliest differentiated cochlear neurons therefore project to a sensory epithelium without mature hair cells. Consequently, basal turn cochlear neurons must be supported initially by neurotrophins that are released from other epithelial cell types. Only $N T-3$, but not $B D N F$, is predominantly expressed in nonhair cells (Figs. 5, 6) (Pirvola et al., 1992) and can thus support cochlear neurons in the basal turn until E15.5 (Fig. 7).

Our results indicate that cochlear neurons in the basal turn degenerate in the absence of NT-3 because BDNF is not expressed in the basal turn epithelium at a critical time. As predicted by this interpretation, transgenic expression of $B D N F$ under control of the NT-3 promoter qualitatively rescues this innervation deficit at E13.5 (Fig. 2D). A similar rescue has been found in newborn transgenic mice (Coppola et al., 2001). However, we cannot exclude the possibility that the additional availability of excess BDNF in itself is related to the observed rescue. Nevertheless, because there is some endogenous expression of $B D N F$ in developing hair cells of the middle and apical turns, sensory neurons innervating these regions are partially rescued by this neurotrophin in NT-3 null mutants. BDNF expression, though, must not be high enough to compensate completely for the loss of NT-3. The specific loss of cochlear neurons in the apical turn of $B D N F$ homozygous mutants may reflect insufficient expression of NT-3 at an early stage. These details have not been recognized in previous in situ studies that either did not cover some of the critical stages or did not examine the basal turn because of the section plane (Pirvola et al., 1992; Wheeler et al., 1994).

We have also detected neurotrophin expression very early in cells delaminating from the otocyst (Fig. 4). Experimental data strongly suggest that all inner ear sensory neurons derive from the otocyst (d'Amico-Martel and Noden, 1983; Fritzsch et al., 1998a). In situ hybridization in mice have suggested that cells in this region of the otocyst wall express FGF-3 (int-2) (Mansour et al., 1993; McKay et al., 1996), FGF10 (Pirvola et al., 2000), GATA3 (Karis et al., 2001), NeuroD (Kim et al., 2001), BF1 (Hatini et al., 1999), and ngn1 (Ma et al., 2000), although double in situ labeling is needed to determine if all these molecules are expressed in the same cells. Delaminated cells migrate rapidly away and undergo further proliferation before aggregating to form the postmitotic otic (cochleovestibular) sensory neurons (Altman and Bayer, 1982; Carney and Silver, 1983; Adam et al., 1998).

Previous in situ hybridization analyses in rats indicated that these cells do not express the neurotrophins BDNF and NT-3 (Pirvola et al., 1992) or their receptors trkB and trkC during migration, but show expression of trkA (Fritzsch et al., 1999). Limited data in mice show some expression of BDNF mRNA in sensory neurons (Schecterson and Bothwell, 1994). Here we show that, although these delaminating cells do not express detectable levels of $t r k \mathrm{~B}$ or $t r k \mathrm{C}$, they do express $N T-3$ and/or BDNF. It seems likely that $N T-3$ and $B D N F$ expression can be more readily detected with the lac $Z$ reporter than by in situ hybridization (Fritzsch et al., 1999; Vigers et al., 2000). BDNF and NT-3 are first induced in delaminating cells, thus suggesting that the expression of NT-3 and BDNF in these migratory cells is genuine and does not reflect the presence of the reporter protein after the $B D N F$ or NT-3 mRNA has disappeared.

These delaminating cells remain spatially segregated from the postmitotic neurons that constitute the otic ganglion and disappear after completion of neurogenesis. Differentiated embryonic otic neurons do not express $N T-3$ or $B D N F$, indicating that 
neurotrophin expression is downregulated on neuronal differentiation. However, otic neurons express $\operatorname{trk} B$ and $t r k C$ (Pirvola et al., 1992), and their neurites grow toward the sensory epithelium across the territory of neurotrophin-expressing precursor cells. Therefore, it is possible that postmitotic neurons in the otic ganglion may rely for initial support on $N T-3$ or $B D N F$ provided by cells present in the pathways traversed by their axons.

Sensory neurons extend processes to their targets in the basal turn before degenerating in the absence of NT-3. The delay of $\sim 1$ $\mathrm{d}$ between initial fiber outgrowth and fiber loss in neurotrophin mutants is comparable with that observed in the semicircular canals of trkB mutants (Fritzsch et al., 1995) and BDNF mutants (Bianchi et al., 1996). Studies in double BDNF/NT-3 or trkB/trkC mutants are needed to determine whether initial outgrowth requires neurotrophin support as previously suggested (Fritzsch et al., 1997a).

In summary, we propose that basal turn cochlear neurons die in the absence of NT-3 because it is the only neurotrophin available to support these neurons during their initial innervation of the cochlea. The opposed temporal gradients of cochlear neuron and hair cell mitosis and differentiation (Ruben, 1967; Pujol et al., 1998) transform a temporal gradient of neurotrophin expression into a spatial gradient of innervation loss (Fig. 7). The basal turn of mammals represents a unique extension of the high-frequency range absent in other vertebrates (Fay, 1992). Development of neurons in this region requires NT-3, which is hardly expressed in the developing avian ear (Pirvola et al., 1997). This suggests that acquisition of novel parts of the cochlea is accompanied by a novel implementation of an existing neurotrophin.

In this paper, we have shown that the developmental dynamics of neurotrophin expression during cochlear development can explain the gradient of neuronal loss observed in the NT-3 mutant. Comparable dynamics of expression of NT-3 and other neurotrophins are similarly likely to explain the patterns of neuronal loss in the trigeminal and dorsal root ganglia. In each case, absence of NT-3 has been shown to result in loss of neurons expressing $\operatorname{Trk} \mathrm{B}$ that are not lost in the absence of $\operatorname{TrkC}$ and therefore appear to be activated directly by NT-3 signaling through TrkB (Fariñas et al., 1998; Huang et al., 1999). Neurons expressing TrkB are lost immediately after neurogenesis. NT-3 is expressed in the mesenchyme immediately adjacent to these ganglia during the period of neurogenesis. As development proceeds, NT-3 is observed in proliferating mesenchyme in limb bud and elsewhere, but expression is lost in most of the differentiated cells derived from this mesenchyme (Fariñas et al., 1998; Patapoutian et al., 1999). In contrast, BDNF expression is not observed in the mesenchyme immediately adjacent to the ganglia or in many of the regions subsequently invaded by sensory fibers (E. Huang, K. R. Jones, and L.F. Reichardt, unpublished observations). Thus, although these neurons eventually innervate targets expressing $B D N F$, transient loss of trophic support results in apoptosis. In the future, it will be essential to understand the mechanisms that regulate the dynamic expression of the various neurotrophins if we are to understand the patterns of neuronal loss observed in wild-type and mutant animals (Patapoutian et al., 1999).

\section{REFERENCES}

Adam J, Myat A, LeRoux I, Eddison M, Henrique D, Ish-Horowicz D, Lewis J (1998) Cell fate choices and the expression of Notch, Delta and Serrate homologues in the chick inner ear: parallel with Drosophila sense-organ development. Development 125:4645-4654.
Altman J, Bayer S (1982) Development of the cranial nerve ganglia and related nuclei in the rat. Adv Anat Embryol Cell Biol 74:1-90.

Bennett JL, Zeiler SR, Jones KR (1999) Patterned expression of BDNF and NT-3 in the retina and anterior segment of the developing mammalian eye. Invest Ophthalmol Vis Sci 40:2996-3005.

Bianchi LM, Conover JC, Fritzsch B, De Chiara T, Lindsay RM, Yancopoulos GD (1996) Degeneration of vestibular neurons in late embryogenesis of both heterozygous and homozygous BDNF null mutant mice. Development 122:1965-1973.

Carney PR, Silver J (1983) Studies on cell migration and axon guidance in the developing distal auditory system of the mouse. J Comp Neurol 215:359-369

Coppola V, Kucera J, Palko MP, Martinez-De Velasco J, Lyons WE, Fritzsch B, Tessarollo L (2001) Dissection of NT-3 functions in vivo by gene replacement strategy. Development, in press.

d'Amico-Martel A, Noden DM (1983) Contribution of placode and neural crest cells to avian cranial peripheral ganglia. Am J Anat 166:445-468.

Ernfors P, van de Water T, Loring J, Jaenisch R (1995) Complementary roles of BDNF and NT-3 in vestibular and auditory development. Neuron 14:1153-1164.

Fariñas I, Jones KR, Backus C, Wang X-Y, Reichardt LF (1994) Severe sensory and sympathetic deficits in mice lacking neurotrophin-3. Nature 369:658-661.

Fariñas I, Yoshida CK, Backus C, Reichardt LF (1996) Lack of neurotrophin-3 results in death of spinal sensory neurons and premature differentiation of their precursors. Neuron 17:1065-1078.

Fariñas I, Wilkinson GA, Backus C, Reichardt LF, Patapoutian A (1998) Characterization of neurotrophin and Trk receptor functions in developing sensory ganglia: direct NT-3 activation of TrkB neurons in vivo. Neuron 21:325-334.

Fay RR (1992) Structure and function in sound discrimination among vertebrates. In: The evolutionary biology of hearing (Webster DB, Popper AN, Fay RR, eds), pp 229-268. New York: Springer.

Fritzsch B, Nichols DH (1993) DiI reveals a prenatal arrival of efferents at the differentiating otocyst of mice. Hear Res 65:51-60.

Fritzsch B, Silos-Santiago I, Smeyne,R, Fagan AM, Barbacid M (1995) Reduction and loss of inner ear innervation in trkB and trkC receptor knockout mice: a whole mount DiI and scanning electron microscopic analysis. Aud Neurosci 1:401-417.

Fritzsch B, Silos-Santiago I, Bianchi LM, Fariñas I (1997a) The role of neurotrophic factors in regulating inner ear innervation. Trends Neurosci 20:159-165.

Fritzsch B, Silos-Santiago I, Bianchi LM, Fariñas I (1997b) Neurotrophins, neurotrophin receptors and the maintenance of the afferent inner ear innervation. Sem Cell Dev Biol 8:277-284.

Fritzsch B, Fariñas I, Reichardt LF (1997c) Lack of NT-3 causes losses of both classes of spiral ganglion neurons in the cochlea in a regionspecific fashion. J Neurosci 17:6213-6225.

Fritzsch B, Fariñas I, Reichardt LF (1997d) The development of NT-3 expression as revealed with a Lac-Z reporter and of innervation deficits in NT-3 mutant mice. Soc Neurosci Abstr 23:881.

Fritzsch B, Barald K, Lomax M (1998a) Early embryology of the vertebrate ear. In: Development of the auditory system, Springer handbook of auditory research (Rubel EW, Popper AN, Fay RR), pp 80-145. New York: Springer.

Fritzsch B, Barbacid M, Silos-Santiago I (1998b) The combined effects of trkB and trkC mutations on the innervation of the inner ear. Int $\mathrm{J}$ Dev Neurosci 16:493-505.

Fritzsch B, Pirvola U, Ylikoski J (1999) Making and breaking the innervation of the ear: neurotrophic support during ear development and its clinical implications. Cell Tissue Res 295:369-382.

Fritzsch B, Fariñas I, Jones KJ, Tessarollo L, Reichardt LF (2000) The spatio-temporal expression of BDNF and NT-3 causes topological restricted spiral ganglion loss: no hair cell specificity in sight. ARO Abstract 23:147-148.

Hatini V, Ye X, Balas G, Lai E (1999) Dynamics of placodal lineage development revealed by targeted transgene expression. Dev Dyn 215:332-343.

Huang EJ, Wilkinson GA, Farinas I, Backus C, Zang K, Wong SL, Reichardt LF (1999) Expression of Trk receptors in the developing mouse trigeminal ganglion: in vivo evidence for NT-3 activation of TrkA and TrkB in addition to TrkC. Development 126:2191-2203.

Karis A, Pata I, van Doorninck H, Grosveld F, de Zeeuw C, de Caprona D, Fritzsch B (2001) GATA-3 alters pathway selection of olivocochlear neurons and affects morphogenesis of the ear. J Comp Neurol 429:615-630.

Kim W-Y, Fritzsch B, Serls A, Bakel LA, Huang EJ, Reichardt LF, Barth DS, Lee JE (2001) NeuroD-null mice are deaf due to a severe loss of the inner ear sensory neurons during development. Development 128:417-426.

Liebl DJ, Tessarollo L, Palko ME, Parada LF (1997) Absence of sensory neurons before target innervation in brain-derived neurotrophic factor-, neurotrophin3-, and trkC-deficient embryonic mice. J Neurosci 17:9113-9127. 
Ma Q, Anderson DJ, Fritzsch B (2000) Neurogenin 1 null mutant ears develop fewer, morphologically normal hair cells in smaller sensory epithelia devoid of innervation. JARO 1:129-143.

Mansour SL, Goddard JM, Capecchi MR (1993) Mice homozygous for a targeted disruption of the proto-oncogene int- 2 have developmental defects in the tail and inner ear. Development 117:13-28.

McKay IJ, Lewis J, Lumsden A (1996) The role of FGF-3 in early inner ear development: an analysis in normal and Kreisler mutant mice. Dev Biol 174:370-378.

Minichiello L, Piehl F, Vazquez E, Schimmang T, Hökfelt T, Represa J, Klein R (1995) Differential effects of combined trk receptor mutations on dorsal root ganglion and inner ear. Development 121:4067-4075.

Morsli H, Choo D, Ryan A, Johnson R, Wu DK (1998) Development of the mouse inner ear and origin of its sensory organs. J Neurosci 18:3327-3335.

Patapoutian A, Backus C, Kispert A, Reichardt LF (1999) Regulation of neurotrophin-3 expression by epithelial-mesenchymal interactions: the role of Wnt factors. Science 283:1180-1183.

Pirvola U, Ylikoski J, Palgi J, Lehtonen E, Arumae U, Saarma M (1992) Brain-derived neurotrophic factor and neurotrophin 3 mRNAs in the peripheral target fields of developing inner ear ganglia. Proc Natl Acad Sci USA 89:9915-9919.

Pirvola U, Arumae U, Moshnyakov M, Palgi J, Saarma M, Ylikoski J (1994) Coordinated expression and function of neurotrophins and their receptors in the rat inner ear during target innervation. Hear Res 75:131-144.

Pirvola U, Hallbook F, Xing-Qun L, Virkkala J, Saarma M, Ylikoski J (1997) Expression of neurotrophins and Trk receptors in the developing, adult, and regenerating avian cochlea. J Neurobiol 33:1019-1033.

Pirvola U, Spencer-Dene B, Xing-Qun L, Kettunen P, Thesleff I, Fritzsch B, Dickson C, Ylikoski J (2000) FGF/FGFR-2(IIIb) signaling is essential for inner ear morphogenesis. J Neurosci 20: 6125-6134.

Pujol R, Lavigne-Rebillard M, Lenoir M (1998) Development of sensory and neural structures in the mammalian cochlea. In: Development of the auditory system (Rubel EW, Popper AN, Fay RR, eds), pp 146-192. New York: Springer.
Ruben RJ (1967) Development of the inner ear of the mouse, a radioautographic study of terminal mitosis. Acta Otolaryngol 220:1-44.

Ryugo DK (1992) The auditory nerve: peripheral innervation, cell body morphology, and central projections. In: The mammalian auditory pathway: neuroanatomy, Springer handbook of auditory research (Webster DB, Popper AN, Fay RR, eds), pp 23-65. New York: Springer.

Schecterson L, Bothwell M (1994) Neurotrophin and neurotrophin receptor mRNA expression in developing inner ear. Hear Res 73:92-100.

Schimmang T, Minichiello L, Vazquez E, San Jose I, Giraldez F, Klein R, Represa J (1995) Developing inner ear sensory neurons require TrkB and TrkC receptors for innervation of their peripheral targets. Development 121:3381-3391.

Schimmang T, Alvarez-Bolado G, Minichiello L, Vazquez E, Giraldez F, Klein R, Represa J (1997) Survival of inner ear sensory neurons in trk mutants. Mech Dev 64:77-85.

Silos-Santiago I, Fagan AM, Garber M, Fritzsch B, Barbacid M (1997) Severe sensory deficits but normal CNS development in newborn mice lacking TrkB and TrkC tyrosine protein kinase receptors. Eur J Neurosci 9:2045-2056.

Sobkowicz HM (1992) The development of innervation in the organ of Corti. In: Development of auditory and vestibular systems (Romand R, ed), pp 59-100. Amsterdam: Elsevier.

Tessarollo L, Tsoulfas P, Donovan MJ, Palko ME, Blair-Flynn J, Hempstead BL, Parada LF (1997) Targeted deletion of all isoforms of the trkC gene suggests the use of alternate receptors by its ligand neurotrophin-3 in neuronal development and implicates trkC in normal cardiogenesis. Proc Natl Acad Sci USA 94:14776-14781.

Vigers AJ, Baquet ZC, Jones KR (2000) Expression of neurotrophin-3 in the mouse forebrain: insights from a targeted LacZ reporter. J Comp Neurol 17:398-415.

Wheeler EF, Bothwell M, Schecterson LC, von Bartheld CS (1994) Expression of BDNF and NT-3 mRNA in hair cells of the organ of Corti: quantitative analysis in developing rats. Hear Res 73:46-56. 